\title{
TRAVESSIAS E TRAVESSURAS FOTOGRÁFICAS, EXPERIMENTOS IMAGÉTICOS POR SÃO JOÃO DEL-REI ${ }^{1}$
}

Ana Tzortzato, Anna Carolina Barcelos, Cassia Resende, Fernanda Omelczuk, Giovana Scareli, Heloísa Lopes, Luciano de Barros, Marli Wunder, Pablo Quaglia, Priscila Fernandes e Tainah Abreu

Oficina, exposição, chão, vento... vento...

nada no lugar, movimento constante

interação, gente animada, passeio

centro histórico, tarde de sol, luz

descoberta do olhar

olhar que paira, desliza, fixa

conversas, risos, casarios

portas, janelas, festas, texturas

e vamos devagar

passos de beira de mundo

corpo cigano e olhar de foto

afeto, um corte

um talhe na pedra

um sol endomingado

a pele de água cinzenta

rebate na lente e mostra

rasgo de acontecimento

num plano

a memória que volta

o momento que cria

expresso foto e grafia

fotografia escultura

corpo vivo

\footnotetext{
${ }^{1}$ Esse artigo traz composições imagéticas da oficina "Travessias fotográficas" oferecida pela fotógrafa Marli Wunder no $7^{\circ}$ Encontro com Imagens e Filosofias, realizado na Universidade Federal de São João del-Rei (MG). As composições e poema foram criados pelos(as) participantes da oficina, autores(as) deste artigo.
} 
deixa de ser plana

ganha peso e ranhuras

textura, corte e cicatriz

ativam a superfície

que queria ser passado

um esquecimento ativo

afirma o presente vivo

da imagem passagem

pura travessia
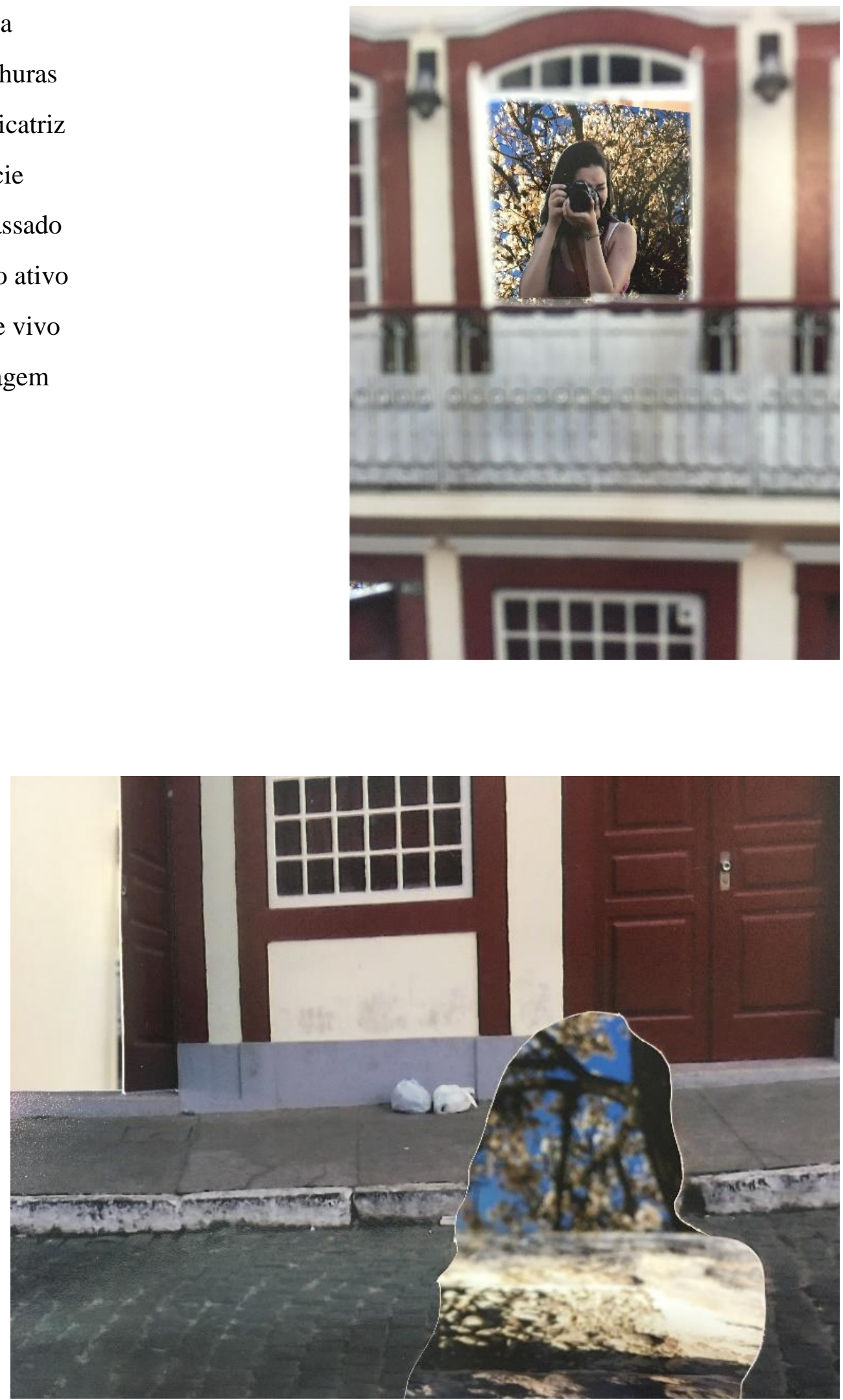

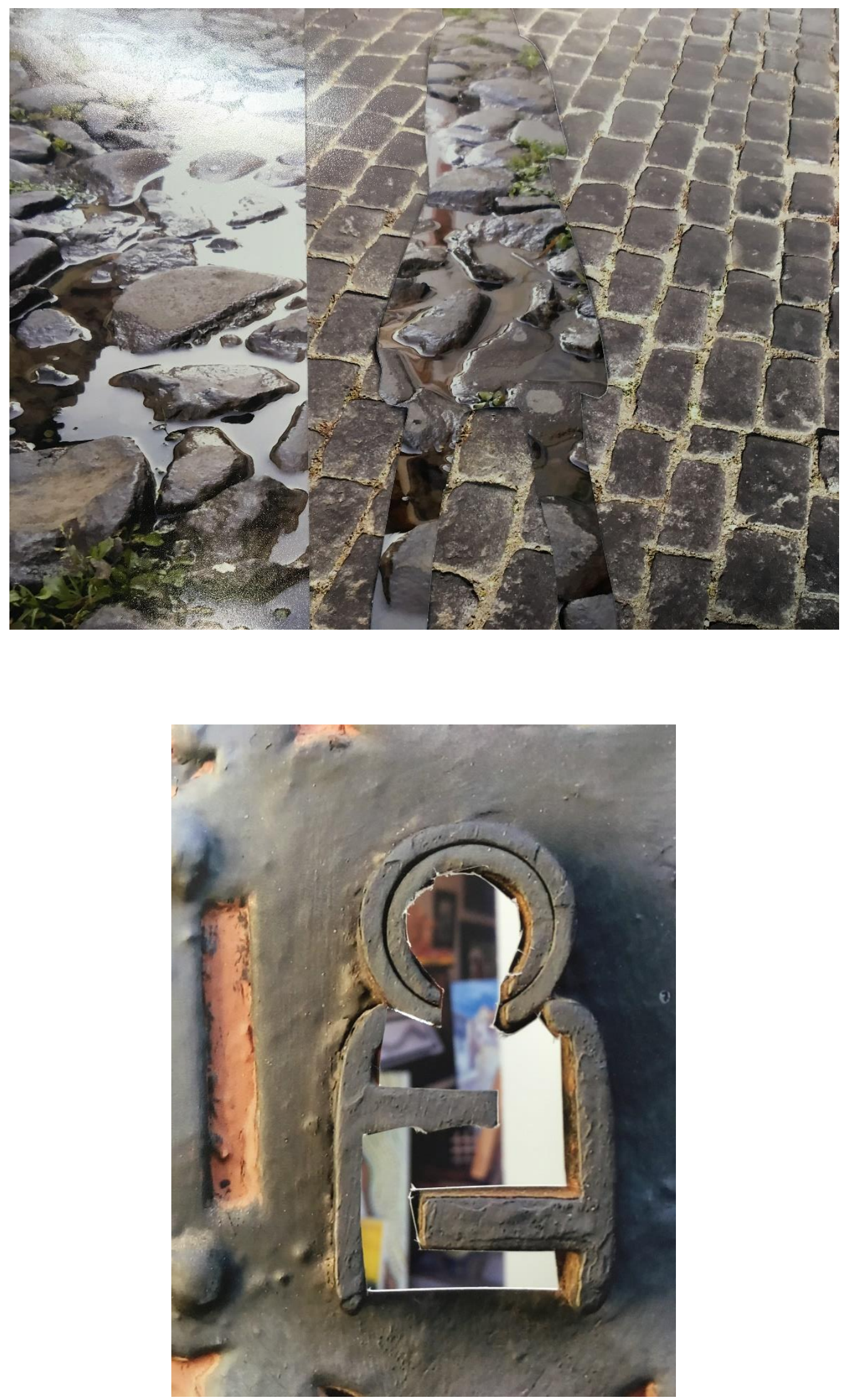


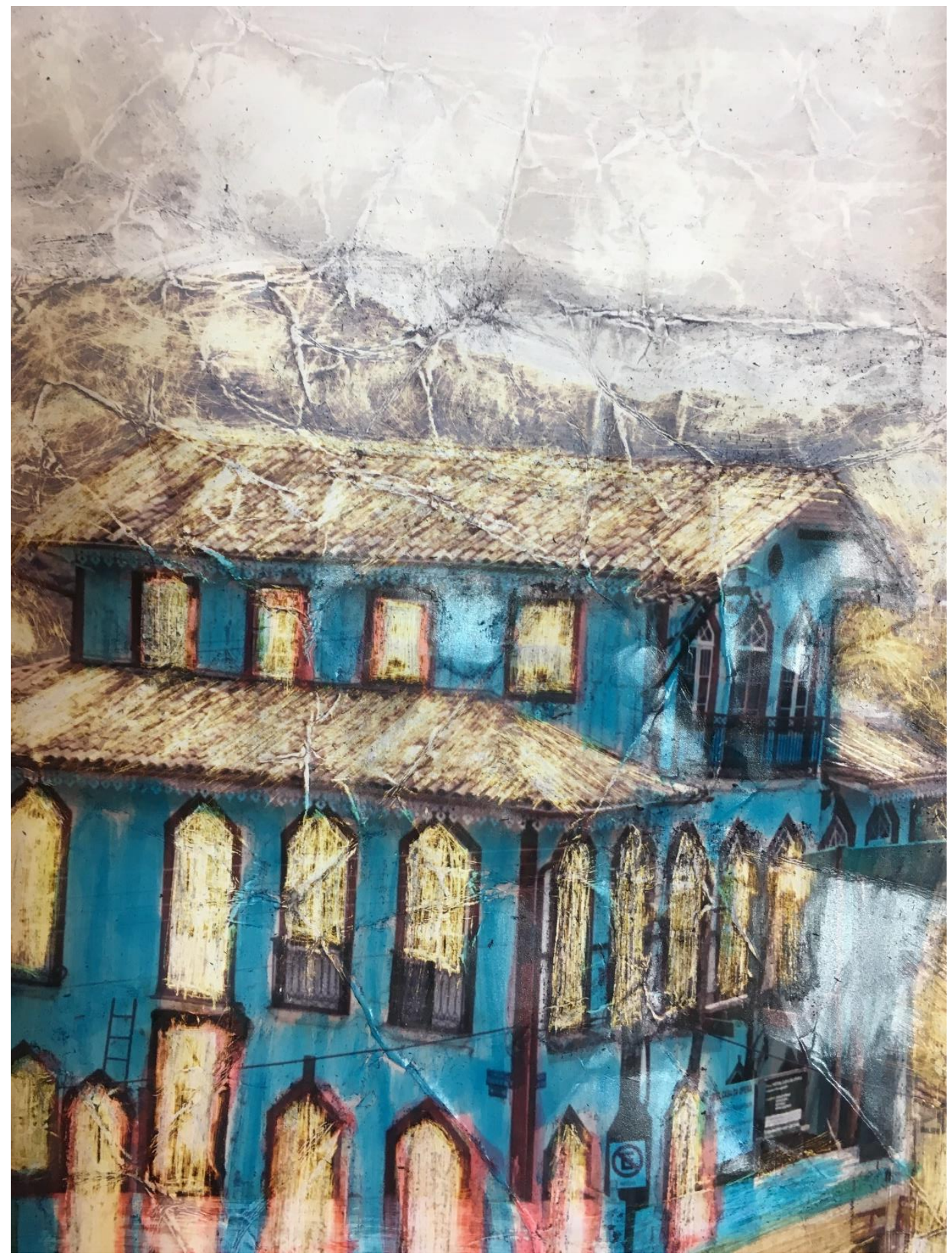



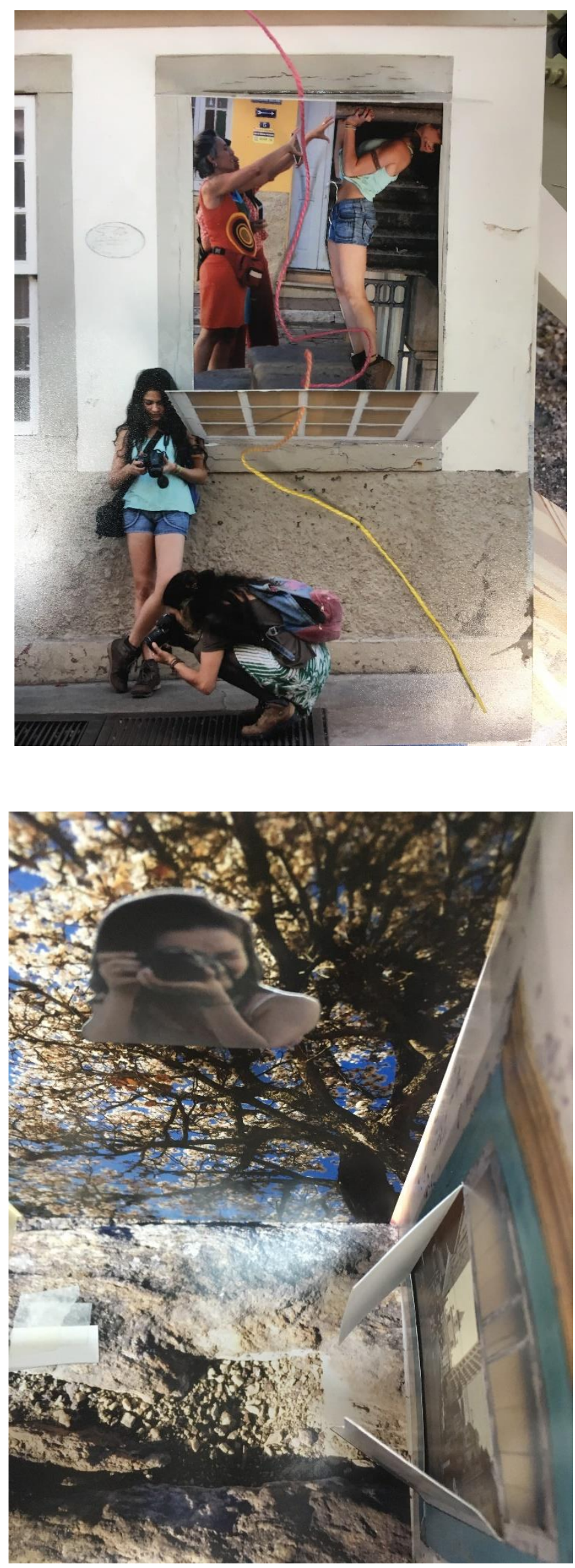

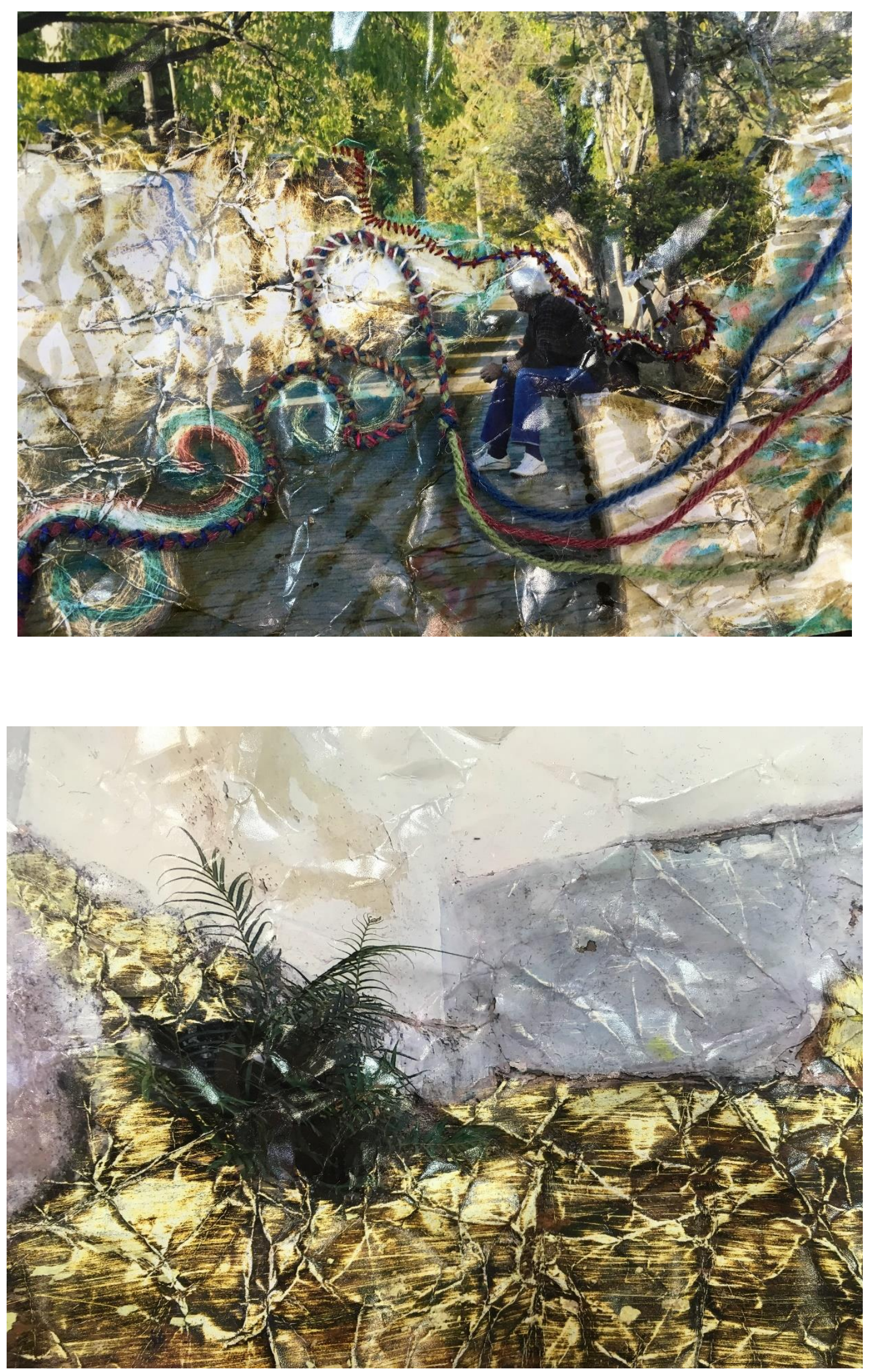

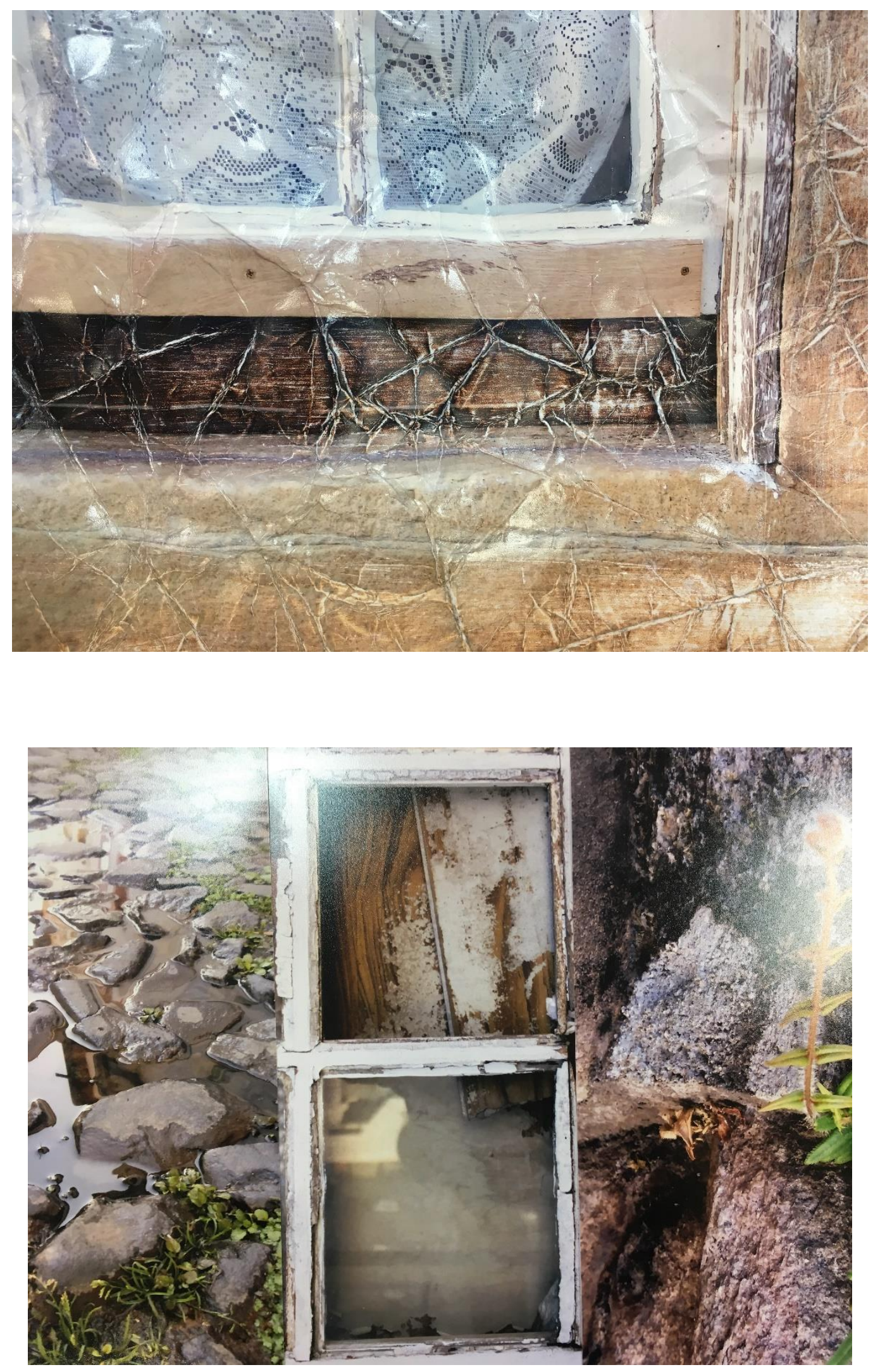

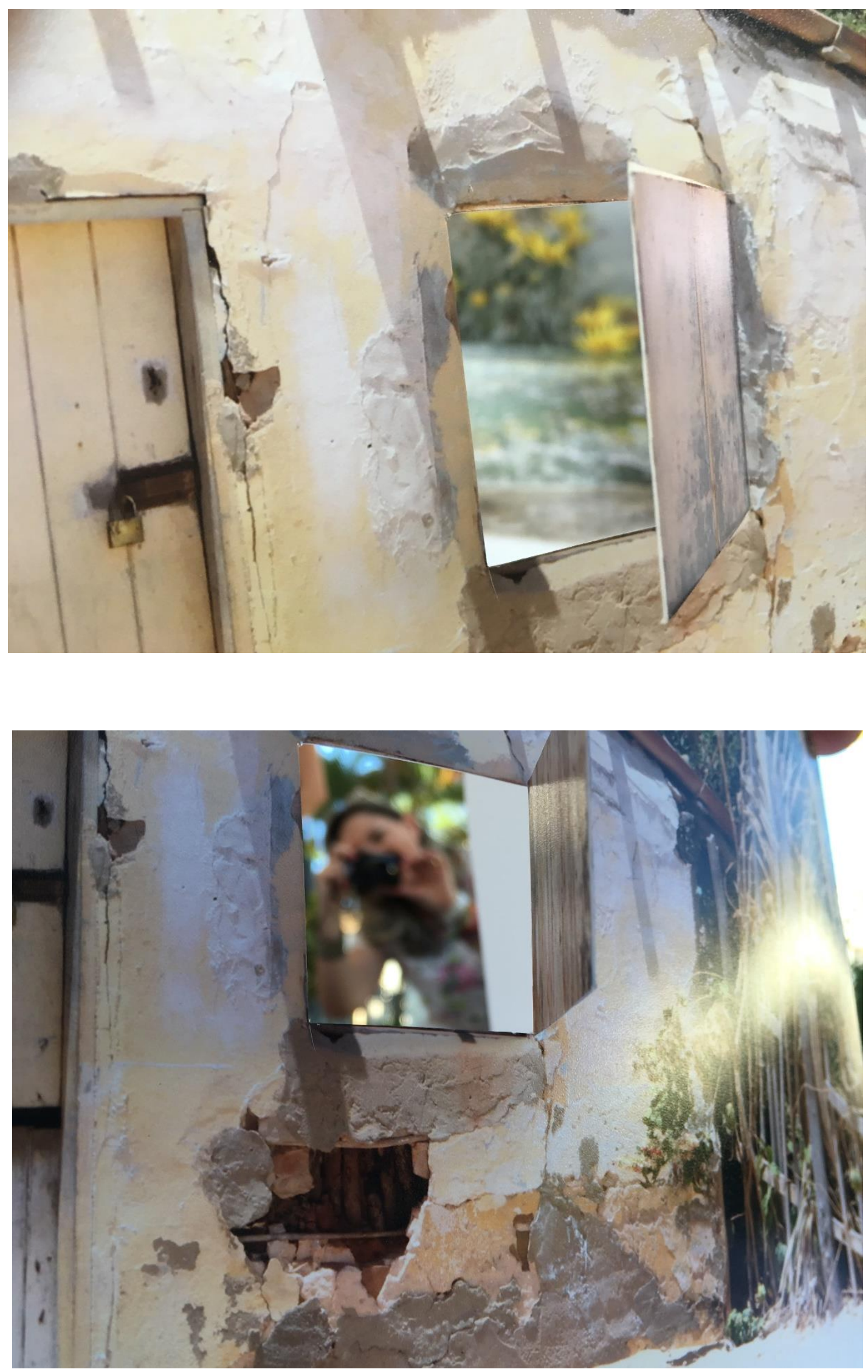

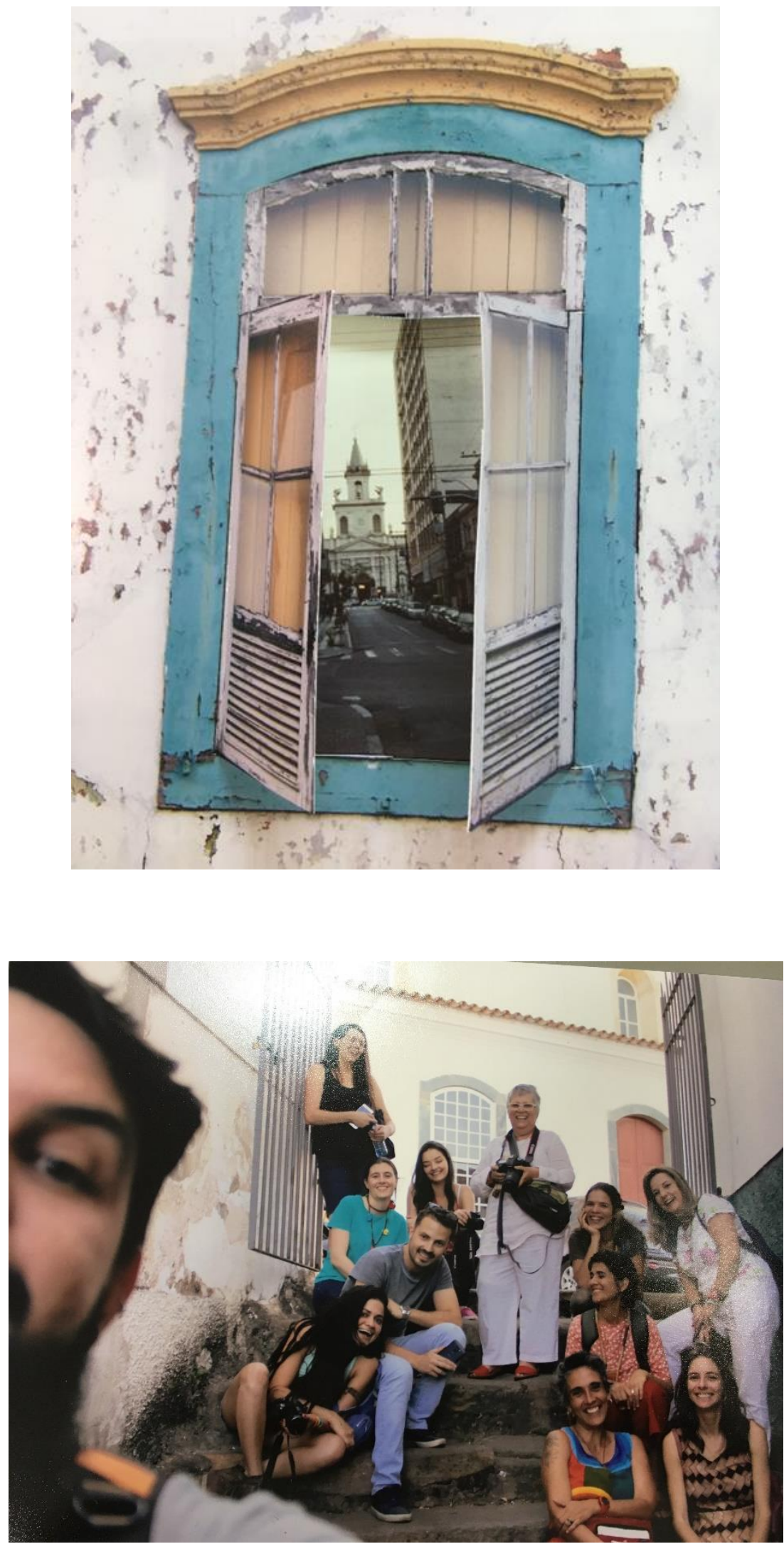